\title{
O Vírus da Imunodeficiência Humana em áreas rurais: reflexões na ótica do acesso
}

\section{aos serviços de saúde}

The Human Immunodeficiency Virus in rural areas: reflections from the perspective of access to

\author{
health services
}

El Virus de la Inmunodeficiencia Humana en el medio rural: reflexiones desde la perspectiva del acceso a los servicios de salud

Iago Orleans Pinheiro Monteiro ORCID: https://orcid.org/0000-0002-2173-0921 Universidade de São Paulo, Brasil E-mail: orleansiago@ hotmail.com

Esmirna Hita Cynara de Amorim Marques Leite ORCID: https://orcid.org/0000-0003-0959-9411 Secretaria Municipal de Saúde de Manacapuru, Brasil E-mail: hita_cynara@hotmail.com

Maria do Socorro Sobreira da Costa ORCID: https://orcid.org/0000-0001-5186-5088 Secretaria Municipal de Saúde de Manacapuru, Brasil E-mail: hebemoura@hotmail.com

Lineker da Silva Souza

ORCID: https://orcid.org/0000-0002-8423-3105 Secretaria Municipal de Saúde de Manacapuru, Brasil E-mail: lineker.odonto@gmail.com

Everton de Oliveira Pinto

ORCID: https://orcid.org/0000-0003-3977-273X

Universidade Federal do Amazonas, Brasil E-mail: everton.oliveira-@ hotmail.com

Gilsirene Scantelbury de Almeida ORCID: https://orcid.org/0000-0003-2153-5330 Universidade Federal do Amazonas, Brasil E-mail: gscantelbury@gmail.com Priscilla Mendes Cordeiro

\begin{abstract}
Resumo
Introdução: As áreas rurais são objeto de negligências sociais evidentes que refletem no contexto da saúde pública, resultado da caracterização, especificidade e concentração dos serviços nos grandes centros urbanos. Esses fatores corroboram para a disseminação de doenças nessas localidades, a exemplo do HIV/AIDS que vem sofrendo um processo de "interiorização" ao longo dos anos. Objetivo: Este trabalho objetivou analisar na literatura a gestão das ações de combate ao Vírus da Imunodeficiência Humana (HIV) em áreas rurais, com foco no acesso dos indivíduos dessas localidades. Metodologia: Realizou-se uma Revisão Integrativa da Literatura nas bases de dados PubMed e BVS, resultando a busca em 18 artigos que atenderam aos critérios de inclusão e exclusão. Resultados: Os estudos destacaram o distanciamento dos serviços como barreira para o acesso, além do foco das ações para mulheres. O estigma social foi um fator relevante para a não adesão dos usuários aos serviços. Conclusão: A população rural ainda convive com déficits no acesso aos serviços de saúde, faz-se então necessária a criação de estratégias que considerem as especificidades dos indivíduos que convivem nesse contexto, principalmente com foco no combate ao HIV/AIDS.

Palavras-chave: HIV; Saúde pública; População rural; Acesso à saúde.
\end{abstract}

\begin{abstract}
Introduction: Rural areas are the object of evident social negligence that reflects in the context of public health, as a result of the characterization, specificity and concentration of services in large urban centers. These factors corroborate the spread of diseases in these locations, such as HIV/AIDS, which has been undergoing a process of "internalization" over the years. Objective: This study aimed to analyze, in the literature, the management of actions to counter the Human Immunodeficiency Virus (HIV) in rural areas, emphasizing the access of individuals in these
\end{abstract}


locations. Methodology: An Integrative Literature Review was carried out in the PubMed and BVS databases, with the research resulting in 18 articles that met the inclusion and exclusion criteria. Results: The studies highlighted the apartment of services as a barrier to access, moreover the focus of actions for women. The social stigma was a relevant factor for users' non-adherence to services. Conclusion: The rural population still lives with deficits in access to health services, so it is necessary to create strategies that consider the specificities of individuals who live in this context, mainly with a focus on combating HIV/AIDS.

Keywords: HIV; Public health; Rural population; Access to health.

\begin{abstract}
Resumen
Introducción: El ámbito rural es objeto de una evidente negligencia social que se refleja en el contexto de la salud pública, como consecuencia de la caracterización, especificidad y concentración de los servicios en los grandes centros urbanos. Estos factores corroboran la propagación de enfermedades en estos lugares, como el VIH / SIDA, que ha venido experimentando un proceso de "internalización" a lo largo de los años. Objetivo: Este estudio tuvo como objetivo analizar en la literatura el manejo de acciones para combatir el Virus de Inmunodeficiencia Humana (VIH) en áreas rurales, enfocándose en el acceso de individuos en estas localidades. Metodología: Se realizó una Revisión Integrativa de Literatura en las bases de datos PubMed y BVS, resultando una búsqueda de 18 artículos que cumplieron con los criterios de inclusión y exclusión. Resultados: Los estudios destacaron el distanciamiento de los servicios como barrera de acceso, además del foco de acciones para las mujeres. El estigma social fue un factor relevante para la no adherencia de los usuarios a los servicios. Conclusión: La población rural aún vive con déficits en el acceso a los servicios de salud, por lo que es necesario crear estrategias que consideren las especificidades de las personas que viven en este contexto, especialmente con un enfoque en el combate al VIH / SIDA.
\end{abstract}

Palabras clave: VIH; Salud pública; Población rural; Acceso a la salud.

\title{
1. Introdução
}

A população mundial está inserida em variados contextos de vivência e esses cenários são subdivididos em zonas urbanas e rurais. De acordo com dados das Nações Unidas, a perspectiva da população mundial no meio do ano de 2020 é de 7.794.799.000 pessoas, concentrando na zona urbana 56,2\% desse total, contraposto por 43,8\% vivendo na zona rural (United Nations, 2019).

Apesar de uma expressiva quantidade de pessoas que habitam nas localidades rurais, ainda há grande dificuldade de conceituar esse espaço. Habitar na zona rural é experienciar uma singularidade de práticas e cenários que diferem do contexto urbano e por vezes, espaços não desenvolvidos e longe dos grandes centros comerciais. Dessa forma, esse tem sido o fundamento para a conceituação mais utilizada para se referir ao rural, estar distante dos grandes centros urbanos (Bennett et al, 2019).

No Brasil, a definição adotada pelo Instituto Brasileiro de Geografia e Estatística (IBGE) para caracterizar o que configura cada um destes dois territórios (urbano e rural), parte de uma lógica residual em relação ao rural, tomando o mesmo conceito disposto no Decreto Lei $\mathrm{N}^{\mathrm{o}} 311 / 38$, onde considera-se como rural todo o território que não pertence à sede do município (perímetro urbano), ficando a essa delimitação a cargo das legislações municipais (Sousa; Monteiro \& Bousquat, 2019).

Essa lógica residual que coloca o centro urbano no centro das definições, somada ao contexto de mercado que prioriza os grandes centros urbanos corrobora para a invisibilidade do contexto rural, refletindo na implementação e execução de serviços essenciais que alcancem a população, incluindo a oferta de saúde (Starfield, 2011). Esses fatores são ainda mais expressivos quando se considera a diversidade populacional existente no espaço rural e as especificidades dessa população que condizem, por exemplo, ao meio de locomoção por rios e estradas de barro. (Arruda; Maia \& Alves, 2018)

Para Probst, Eberth e Crouch (2019) as iniquidades em saúde nas regiões rurais são reflexo do urbanismo estrutural (viés de atenção para os centros com grandes concentrações populacionais). Ademais, a baixa disponibilidade de profissionais de saúde nesse contexto agrava ainda mais a problemática.

Entre as estratégias governamentais para superar essas dificuldades, destaca-se a criação de políticas equânimes no Sistema Único de Saúde brasileiro, a exemplo da Política Nacional de Saúde Integral das Populações do Campo, da Floresta e 
das Águas (PNSIPCFA), que englobando a população da zona rural teve sua implementação responsável por grandes avanços na constituição e na prática do SUS. Todavia, permanece o desafio para a gestão do sistema de considerar a dinâmica e a diversidade própria dos espaços não urbanos, com vista a ampliar o campo de acesso da população rural aos serviços de saúde (Souto et al, 2016).

Assim, considerando todo esse quadro de iniquidades e desigualdades presentes no contexto rural em relação aos serviços de saúde, esse ambiente torna-se propício para a propagação de doenças. Segundo Sousa, Monteiro e Bosquat (2019), há uma dificuldade na prevenção de doenças e agravos em populações rurais, que somada a fatores específicos de cada território, podem culminar para a epidemia de infecções entre os habitantes.

Porquanto, a exemplo disso, tem-se a infecção pelo Vírus da Imunodeficiência Humana (HIV), causador da Síndrome da Imunodeficiência Adquirida (AIDS). Segundo a Organização Mundial da Saúde (OMS), o HIV representa um problema de saúde pública ao redor do mundo, afirmando que mais de 78 milhões de pessoas foram infectadas e as ações de combate à disseminação do vírus devem ser contínuas, priorizando o diagnóstico precoce e o acesso da população ao tratamento, com vista a diminuição do contágio (WHO, 2019).

De acordo com Souza et al. (2013), a AIDS é um dos mais graves problemas da atualidade e vem passando por alguns processos sociais ao longo do tempo, como é o fato da interiorização, ou seja, o aumento do número de casos diagnosticados nas regiões mais distantes dos centros urbanos.

Percebe-se que nas áreas rurais, fatores como processo de migração rural-urbana, baixa escolaridade e carência de informação através dos meios de comunicação de forma mais específica para a realidade destes, tornam-se influenciadores para a disseminação do vírus (Alves, 2003; Kerr-Pontes et al, 2004; Guimarães; Martin \& Quirino, 2007).

Apesar da necessidade de pesquisas, que criem um delineamento científico, que possa subsidiar a criação de políticas públicas voltadas para a prevenção e controle da doença no contexto rural, ainda são reduzidos os estudos referentes a esse processo. (Souza et. al, 2013)

Nesse sentido, essa pesquisa se propõe como uma medida que aumente a óptica do impacto do HIV/AIDS em áreas pouco discutidas, como no território rural, propondo a abordagem para os novos rumos que a doença vem tomando.

Portanto, compreendendo a necessidade de abordar o HIV/AIDS na realidade da população rural, diante das problemáticas expostas, propõe-se neste estudo um olhar a partir da literatura voltado para o acesso dos usuários aos serviços de prevenção, diagnóstico e tratamento de HIV em nível mundial para uma reflexão do território brasileiro.

Como definição de acesso, adotamos a conceituação proposta por Giovanella e Fleury (1996) que divide o acesso em cinco dimensões. A primeira refere-se à disponibilidade do serviço e à necessidade destacada pelos indivíduos para procurar este. A segunda, a acessibilidade às ações disponibilizadas. Posteriormente, a adequação desses serviços à realidade da População. A quarta dimensão diz respeito à capacidade financeira dos indivíduos em ter acesso. Por fim, a quinta promove aceitabilidade dos usuários frente aos serviços ofertados.

Dessa forma, este estudo objetiva analisar na literatura a gestão das ações de combate ao Vírus da Imunodeficiência Humana (HIV) em áreas rurais, com foco no acesso dos indivíduos dessas localidades.

\section{Metodologia}

Trata-se de um estudo descritivo, tipo Revisão Integrativa da Literatura, onde realizou-se análise crítica e aprofundada da literatura relacionada ao tema específico com objetivo de gerar evidências para a reflexão e prática profissional em saúde e áreas correlatas, seguindo as etapas de elaboração da questão norteadora, busca na literatura, coleta de dados, análise dos estudos incluídos, discussão dos resultados e síntese da revisão (Estrela, 2018; Colin et al, 2017). 
O estudo foi orientado pela questão de investigação: "Qual o acesso da população rural aos serviços de prevenção, diagnóstico e tratamento de HIV/AIDS?", elaborada de acordo com a estratégia PICo, um mnemônico onde P= População de interesse; I = Fenômenos de interesse; $\mathrm{Co}=$ Contexto (Aromataris; Munn, 2020). A partir da estratégia, a questão de pesquisa foi operacionalizada, subsidiando a escolha dos descritores da pesquisa, como descrito no Quadro 1.

Quadro 1 - Utilização da Estratégia PICo.

\begin{tabular}{|c|c|c|}
\hline \multicolumn{3}{|c|}{ Qual o acesso da população rural aos serviços de prevenção, diagnóstico e tratamento de } \\
HIV/AIDS?
\end{tabular}

Fonte: Autores.

No Quadro 1 é possível observar que a utilização do mnemônico permitiu operacionalizar a questão de investigação, levando ao levantamento dos descritores MESH e DesC.

A pesquisa foi realizada durante o mês de Fevereiro de 2020. A busca foi realizada nas bases de dados PubMed e BVS. Para a PubMed utilizou-se os Medical Subject Headings (MESH): Health Services Accessibility; HIV Serodiagnosis; HIV; Rural Population. Na BVS utilizou-se os Descritores das Ciências da Saúde (DeCS): Acesso aos serviços de Saúde; Sorodiagnóstico de HIV; HIV; População rural. Destes, os dois últimos descritores foram considerados os principais. Dessa a forma, todas as combinações tiveram como eixo estes 2 descritores. Para a busca utilizou-se em todas as combinações o operador boleano AND, conforme mostra o Quadro 2.

Quadro 2 - Combinações dos descritores para busca.

\begin{tabular}{|l|}
\hline \multicolumn{1}{|c|}{ Medical Subject Headings (MESH) } \\
\hline HIV AND Rural Population AND Health Services Accessibility \\
\hline HIV AND Rural Population AND HIV Serodiagnosis \\
\hline \multicolumn{1}{c|}{ Descritores das Ciências da Saúde (DECS) } \\
\hline HIV AND População Rural AND Sorodiagnóstico de HIV \\
\hline HIV AND População Rural AND Acesso aos serviços de saúde \\
\hline
\end{tabular}

Fonte: Autores.

No Quadro 2 é evidenciada a combinação de descritores utilizadas para a busca nas bases de dados com a inserção dos operadores boleanos AND.

Como critérios de inclusão, foram considerados artigos originais publicados nos últimos cinco anos (2015-2019) nos idiomas português, inglês e espanhol, com texto completo e disponível que versasse sobre HIV em áreas rurais.

O processo de seleção dos artigos incluídos na revisão seguiu as etapas de Identificação, Triagem, Elegibilidade e Inclusão (Moher et al, 2009). Na primeira etapa, a partir das buscas foram identificados 202 artigos. No entanto, 156 foram excluídos a partir da leitura dos títulos e resumos por não atenderem aos critérios de inclusão e por apresentarem artigos repetidos. Por fim, 
verificou-se que apenas 46 atendiam aos critérios de inclusão e, portanto, foram lidos. Destes, apenas 18 foram incluídos na RIL. (Fluxograma 1)

Fluxograma 1 - Etapas de exclusão dos artigos até os 18 artigos inseridos na RIL.

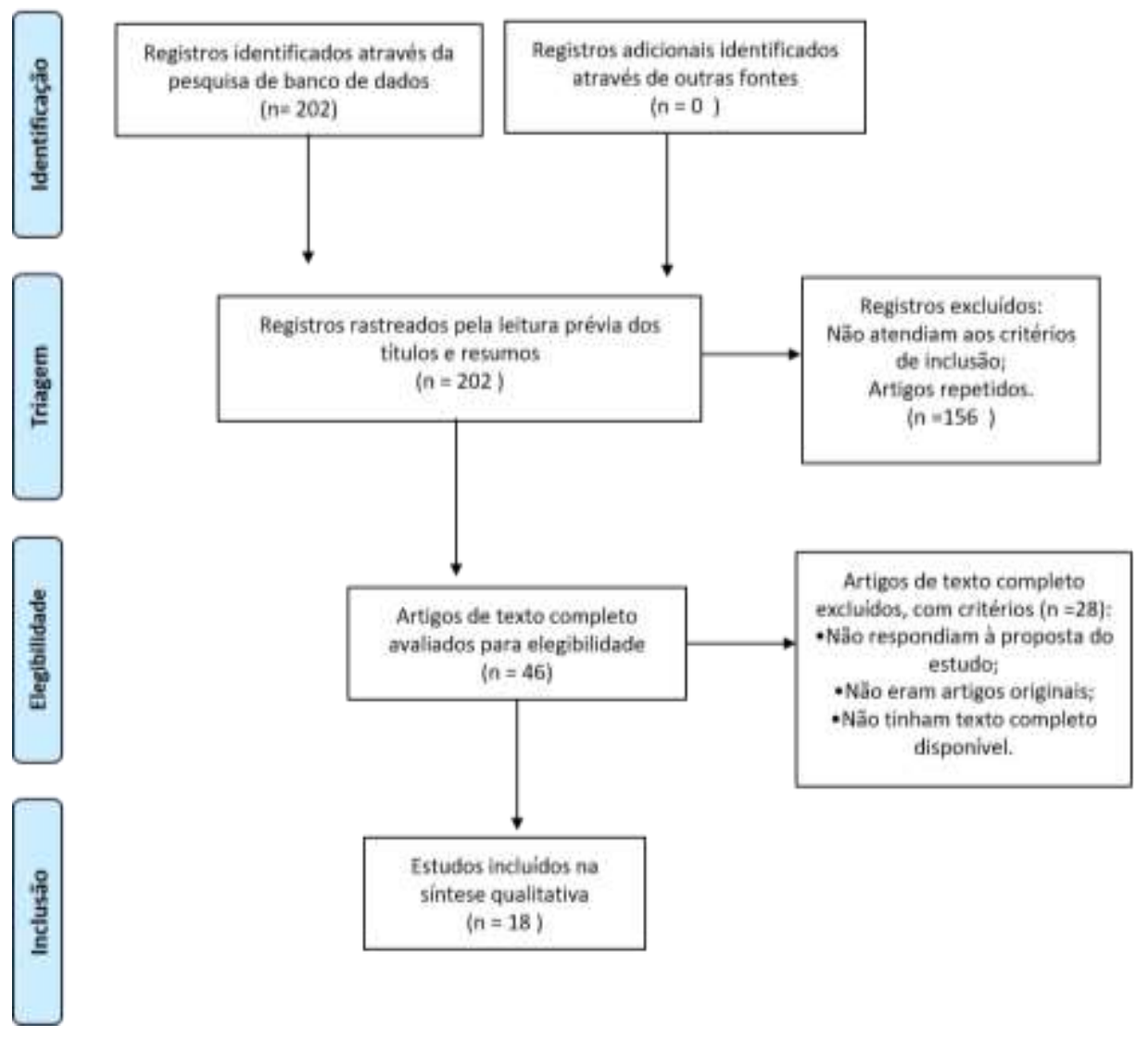

Fonte: Autores.

Após a leitura e análise dos artigos incluídos na revisão, realizou-se a categorização destes para discussão. As categorias que emergiram a partir da leitura dos estudos consideram as dimensões de acesso propostas por Giovanella e Fleury (1996) Dessa forma, ao considerar as relações entre as dimensões em temáticas mais abrangentes, são contempladas e discutidas dentro das categorias, conforme mostra o Quadro 3.

Quadro 3 - Categorias e dimensões de acesso.

\begin{tabular}{|l|l|}
\hline CATEGORIAS & DIMENSÕES DO ACESSO \\
\hline Disponibilidade dos serviços de HIV em áreas rurais & Disponibilidade \\
\hline Barreiras no acesso aos serviços de HIV & Acessibilidade; Capacidade financeira \\
\hline $\begin{array}{l}\text { Adequação dos serviços à realidade da população } \\
\text { rural }\end{array}$ & Adequação funcional; Aceitabilidade; \\
\hline
\end{tabular}

Fonte: Autores. 
Como observado no quadro 3, as categorias utilizadas abrangem as categorias de acesso propostas pelo referencial teórico-metodológico, quais sejam: Disponibilidade dos serviços de HIV em áreas rurais; Barreiras no acesso aos serviços de HIV; Adequação dos serviços à realidade da população rural.

\section{Resultados e Discussão}

Do total de artigos inseridos, na Tabela 1 descreve-se o quantitativo presente em cada base de dados.

Tabela 1 - Apresentação das bases de dados em que os estudos foram levantados.

\begin{tabular}{lccc}
\hline & Base de dados & $\boldsymbol{N}$ & $\boldsymbol{\%}$ \\
\hline PubMed & 17 & 94,4 \\
BVS & 1 & 5,56 \\
Total & $\mathbf{1 8}$ & $\mathbf{1 0 0}$ \\
\hline
\end{tabular}

Fonte: Dados dos artigos da RIL.

Conforme mostra a tabela, $17(94,4 \%)$ artigos da amostra total foram levantados na PubMed e apenas $1(5,6 \%)$ na BVS. Quanto ao tipo de estudo, a Tabela 2 especifica o quantitativo.

Tabela 2 - Apresentação dos tipos de estudos que foram inseridos nesta RIL.

\begin{tabular}{lccc}
\hline & Tipo de estudo & $\boldsymbol{N}$ & $\mathbf{\%}$ \\
\hline Misto & 4 & 22,2 \\
Quanti & 10 & 55,6 \\
Quali & 4 & 22,2 \\
Total & $\mathbf{1 8}$ & $\mathbf{1 0 0}$ \\
\hline
\end{tabular}

Fonte: Dados dos artigos da RIL.

Como observado, verificou-se que entre os estudos, $10(55,6 \%)$ são de abordagem quantitativa, estudos qualitativos e mistos (quantitativo+qualitativos) representaram 4 (22,2\%) cada. Os dados referentes aos idiomas dos estudos estão descritos na Tabela 3 .

Tabela 3 - Apresentação do idioma em que os artigos foram publicados

\begin{tabular}{lccc}
\hline & Idioma & $\boldsymbol{N}$ & $\mathbf{\%}$ \\
\hline Inglês & 17 & 94,4 \\
Português & 1 & 5,56 \\
Total & $\mathbf{1 8}$ & $\mathbf{1 0 0}$ \\
\hline
\end{tabular}

Fonte: Dados dos artigos da RIL.

A tabela revela que $17(94,4 \%)$ estudos foram escritos em inglês e apenas $1(5,6 \%)$ em português. No que diz respeito ao país em que o estudo foi conduzido, a tabela 4 dispõe o quantitativo. 
Tabela 4 - Apresentação da nacionalidade em que os estudos foram produzidos.

\begin{tabular}{|c|c|c|}
\hline Nacionalidade & $N$ & $\%$ \\
\hline EUA & 2 & 11,1 \\
\hline Tanzania & 3 & 16,7 \\
\hline África do Sul & 6 & 33,3 \\
\hline China & 1 & 5,56 \\
\hline Bolívia & 1 & 5,56 \\
\hline Burkina Faso & 1 & 5,56 \\
\hline Zambia & 2 & 11,1 \\
\hline Uganda & 1 & 5,56 \\
\hline Brasil & 1 & 5,56 \\
\hline Total & 18 & 100 \\
\hline
\end{tabular}

Fonte: Dados dos artigos da RIL

Conforme distribuído na tabela, temos que a África do Sul teve a maior quantidade de artigos, com 6 (33,3\%), seguido por Tanzania 3 (16,7\%), Estados Unidos da América e Zambia com 2 (11,1\%), cada, Uganda, China, Bolívia, Brasil e Burkina Faso com 1 (5,6\%). Os dados específicos de cada artigo incluído estão descritos no Quadro 4.

Quadro 4 - Discorre sobre informações necessárias para a identificação dos 18 artigos que compõe os resultados desta RIL.

\begin{tabular}{|c|c|c|c|c|}
\hline $\begin{array}{l}\text { Autores } \\
\text { (ano) }\end{array}$ & Título & País & Objetivo & Conclusão \\
\hline $\begin{array}{l}\text { Hubach, et } \\
\text { al. } \\
(2017)\end{array}$ & $\begin{array}{l}\text { Barriers to access and } \\
\text { adoption of pre- } \\
\text { exposure prophylaxis } \\
\text { for the prevention of } \\
\text { hiv among men who } \\
\text { have sex with men } \\
\text { (msm) in a relatively } \\
\text { rural state }\end{array}$ & EUA & $\begin{array}{l}\text { Avaliar opiniões de e } \\
\text { percebidas barreiras ao acesso } \\
\text { e adoção de PrEP entre MSM } \\
\text { residindo em Oklahoma }\end{array}$ & $\begin{array}{l}\text { O enfrentamento do estigma situado em níveis } \\
\text { ecológicos, em um esforço para aumentar a adoção da } \\
\text { PrEP pelo MSM residente em estados rurais, continua } \\
\text { sendo necessário. Sem isso, os determinantes sociais } \\
\text { podem continuar a influenciar negativamente a PrEP } \\
\text { adoção e resultados de saúde sexual. }\end{array}$ \\
\hline $\begin{array}{l}\text { Baker, et } \\
\text { al.(2015) }\end{array}$ & $\begin{array}{l}\text { Bottlenecks in the } \\
\text { implementation of } \\
\text { essential screening } \\
\text { tests in antenatal care: } \\
\text { Syphilis, HIV, and } \\
\text { anemia testing in rural } \\
\text { Tanzania and Uganda }\end{array}$ & Tanzania & $\begin{array}{l}\text { Identificar e comparar } \\
\text { gargalos de implementação } \\
\text { para uma cobertura eficaz da } \\
\text { triagem para sífilis, HIV e } \\
\text { anemia no pré-natal na } \\
\text { Tanzânia rural e Uganda; e } \\
\text { explorar os determinantes } \\
\text { subjacentes e soluções } \\
\text { percebidas para superar esses } \\
\text { gargalos. }\end{array}$ & $\begin{array}{l}\text { Nossos achados reforçam a triagem essencial como uma } \\
\text { oportunidade perdida, causada pela falta de integração } \\
\text { de financiamento e apoio a programas de pré-natal } \\
\text { abrangentes. }\end{array}$ \\
\hline $\begin{array}{l}\text { Orne- } \\
\text { Gliemann, } \\
\text { et al. }(2016)\end{array}$ & $\begin{array}{l}\text { Community } \\
\text { perceptions of repeat } \\
\text { HIV-testing: } \\
\text { experiences of the } \\
\text { ANRS } 12249 \\
\text { Treatment as } \\
\text { Prevention trial in } \\
\text { rural South Africa }\end{array}$ & $\begin{array}{l}\text { África do } \\
\text { Sul }\end{array}$ & $\begin{array}{l}\text { Investigar as percepções de } \\
\text { repetição testes de HIV entre } \\
\text { as comunidades rurais na } \\
\text { África do Sul antes e durante } \\
\text { as etapas de implementação } \\
\text { antecipada do ensaio ANRS } \\
12249 \text { tratamento como } \\
\text { prevenção (TASP), isto é, } \\
\text { durante um período de } \\
\text { mudanças rápidas de HIV } \\
\text { abordagens de tratamento. }\end{array}$ & $\begin{array}{l}\text { Este estudo sugere vários caminhos para melhorar } \\
\text { Aceitabilidade de testes de HIV, incluindo a } \\
\text { implementação de abordagens diversas e personalizadas } \\
\text { para Teste e cuidado do HIV, e oportunidades para } \\
\text { iniciação e cuidado da terapia antirretroviral Em casa. }\end{array}$ \\
\hline $\begin{array}{l}\text { Smith, et } \\
\text { al.(2017) }\end{array}$ & $\begin{array}{l}\text { Effects of patient load } \\
\text { and travel distance on } \\
\text { HIV transmission in }\end{array}$ & China & $\begin{array}{l}\text { Investigar os papéis da carga } \\
\text { do paciente e da distância de } \\
\text { viagem para Clínica de }\end{array}$ & $\begin{array}{l}\text { A maior carga de pacientes em clínicas de HIV esteve } \\
\text { associada ao risco de transmissão do HIV em nossa } \\
\text { população, particularmente em clínicas de nível de }\end{array}$ \\
\hline
\end{tabular}




\begin{tabular}{|c|c|c|c|c|}
\hline & $\begin{array}{|lr|}\text { rural } & \text { China: } \\
\text { Implications } & \text { for } \\
\text { treatment } & \text { as } \\
\text { prevention } & \end{array}$ & & $\begin{array}{l}\text { tratamento d HIV em risco de } \\
\text { transmissão em casais } \\
\text { sorodiscordantes do HIV na } \\
\text { província de Henan, China. }\end{array}$ & $\begin{array}{l}\text { aldeia. A distância de viagem mais distante teve efeitos } \\
\text { divergentes com base no nível da clínica, sugerindo } \\
\text { mecanismos únicos operando em níveis de } \\
\text { disponibilidade de recursos. A intensidade de recursos } \\
\text { do tratamento de longo prazo do HIV pode colocar } \\
\text { cepas significativas em pequenas clínicas rurais, para as } \\
\text { quais os investimentos em pessoal de apoio adicional } \\
\text { ou ferramentas de economia de tempo, como testes } \\
\text { laboratoriais de ponto de cuidado podem trazer } \\
\text { mudanças impactantes nos resultados do tratamento }\end{array}$ \\
\hline $\begin{array}{l}\text { Treves- } \\
\text { Kagan, et } \\
\text { al. }(2017)\end{array}$ & $\begin{array}{l}\text { Gender, HIV testing } \\
\text { and stigma: The } \\
\text { association of HIV } \\
\text { testing behaviors and } \\
\text { community-level and } \\
\text { individual-level } \\
\text { stigma in rural South } \\
\text { Africa differ for men } \\
\text { and women }\end{array}$ & $\begin{array}{l}\text { África do } \\
\text { Sul }\end{array}$ & $\begin{array}{l}\text { Explorar a relação entre o } \\
\text { estigma antecipado de nível } \\
\text { individual, a prevalência } \\
\text { comunitária de estigma } \\
\text { antecipado e a captação de } \\
\text { testes de HIV por sexo em } \\
\text { uma pesquisa de base } \\
\text { populacional realizada em uma } \\
\text { área rural de alta prevalência } \\
\text { da África do Sul. }\end{array}$ & $\begin{array}{l}\text { Programação deve considerar redução do estigma no } \\
\text { contexto das normas sociais e gênero para adequar } \\
\text { atividades apropriadamente. }\end{array}$ \\
\hline $\begin{array}{l}\text { Calderóna, } \\
\text { et al.(2015) }\end{array}$ & $\begin{array}{l}\text { Knowledge, attitudes } \\
\text { and practices on } \\
\text { HIV/AIDS and } \\
\text { prevalence of HIV in } \\
\text { the general population } \\
\text { of Sucre, Bolivia }\end{array}$ & Bolívia & $\begin{array}{l}\text { Analisar conhecimentos, } \\
\text { atitudes e práticas sexuais } \\
\text { sobre HIV/AIDS e estimar a } \\
\text { prevalência de HIV entre os } \\
\text { residentes em Sucre (Bolívia). }\end{array}$ & $\begin{array}{l}\text { A prevalência de infecção pelo HIV é muito baixa e o } \\
\text { sexo inseguro é relativamente incomum. Conhecimento } \\
\text { inadequado sobre HIV/AIDS e atitudes discriminatórias } \\
\text { em relação ao PLWHA são extremamente elevados e } \\
\text { estão associados às desigualdades de gênero, étnicas e } \\
\text { econômicas. }\end{array}$ \\
\hline $\begin{array}{l}\text { De Allegri, } \\
\text { et al.(2015) }\end{array}$ & $\begin{array}{l}\text { Factors Affecting the } \\
\text { Uptake of HIV } \\
\text { Testing among Men: } \\
\text { A Mixed-Methods } \\
\text { Study in Rural } \\
\text { Burkina Faso }\end{array}$ & $\begin{array}{l}\text { Burkina } \\
\text { Faso }\end{array}$ & $\begin{array}{l}\text { Explorar fatores que } \\
\text { configuram a decisão de } \\
\text { submeter-se ao teste do Vírus } \\
\text { da Imunodeficiência Humana } \\
\text { (HIV) entre homens na zona } \\
\text { rural de Burkina Faso. }\end{array}$ & $\begin{array}{l}\text { Nossos achados sugeriram que o uso de cuidados pré- } \\
\text { natais e serviços curativos como a entrada exclusiva } \\
\text { aponta para o teste de HIV pode não ser suficiente para } \\
\text { atingir grandes parcelas da população masculina. } \\
\text { Assim, são necessárias estratégias adicionais para } \\
\text { aumentar a captação de serviços. }\end{array}$ \\
\hline $\begin{array}{l}\text { Gourlay, et } \\
\text { al.(2015) }\end{array}$ & $\begin{array}{l}\text { Factors associated } \\
\text { with uptake of } \\
\text { services to prevent } \\
\text { mother-to-child } \\
\text { transmission of HIV } \\
\text { in a community cohort } \\
\text { in rural Tanzania }\end{array}$ & Tanzania & $\begin{array}{l}\text { Identificar fatores associado ao } \\
\text { acesso ao cuidado com o HIV } \\
\text { e antirretroviral (ARV) } \\
\text { medicamentos para prevenção } \\
\text { de mãe para filho transmissão } \\
\text { (PMTCT) do HIV entre HIV- } \\
\text { positivo mulheres grávidas em } \\
\text { uma coorte comunitária na } \\
\text { zona rural Tanzânia (Kisesa). }\end{array}$ & $\begin{array}{l}\text { O acesso aos serviços do PMTCT foi baixo neste } \\
\text { ambiente rural, mas melhorou significativamente ao } \\
\text { longo do tempo. Lá eram bastante poucos diferenciais } \\
\text { sociodemográficos, embora apoio para mulheres jovens } \\
\text { e aqueles sem parceiros pode ser necessário. } \\
\text { Descentralização dos serviços de HIV para áreas mais } \\
\text { remotas, promoção de voluntariamente aconselhamento } \\
\text { e testes e implementação da Opção B+ são propensos a } \\
\text { melhorar a captação e pode trazer mulheres em } \\
\text { cuidados e tratamento mais cedo após a infecção }\end{array}$ \\
\hline $\begin{array}{l}\text { Hensen, et } \\
\text { al.(2015) }\end{array}$ & $\begin{array}{l}\text { Frequency of HIV- } \\
\text { testing and factors } \\
\text { associated r with } \\
\text { multiple lifetime HIV- } \\
\text { testing among a rural } \\
\text { population of Zambian } \\
\text { men }\end{array}$ & Zambia & $\begin{array}{l}\text { Explorar a frequência de testes } \\
\text { de HIV entre uma população } \\
\text { rural de homens e os fatores } \\
\text { associado com testes mais } \\
\text { frequentes de HIV. }\end{array}$ & $\begin{array}{l}\text { Embora os níveis de testes para o HIV tenham } \\
\text { aumentado, as estratégias precisam aumentar a vida útil } \\
\text { frequência de teste de HIV entre homens com risco } \\
\text { contínuo de infecção pelo HIV. }\end{array}$ \\
\hline $\begin{array}{l}\text { Sacksa, et } \\
\text { al.(2016) }\end{array}$ & $\begin{array}{lr}\text { Postnatal care } \\
\text { utilization and local } \\
\text { understandings } r \text { of } \\
\text { contagion among } \\
\text { HIVinfected r and } \\
\text { uninfected women in } \\
\text { rural, southern Zambia }\end{array}$ & Zambia & $\begin{array}{l}\text { Examinar as experiências de } \\
\text { acesso das mulheres } \\
\text { assistência pós-natal formal } \\
\text { para seus recém-nascidos } \\
\text { expostos ao HIV, comparando } \\
\text { relatos de infectados pelo HIV } \\
\text { e mulheres não infectadas em } \\
\text { uma área endêmica de HIV no } \\
\text { sul da Zâmbia. }\end{array}$ & $\begin{array}{l}\text { Ao integrar programas para hiv com cuidados de saúde } \\
\text { materno-infantil, essas tensões nuances entre grupos de } \\
\text { pacientes devem ser reconhecido e resolvido. }\end{array}$ \\
\hline $\begin{array}{l}\text { Sanga, } \\
\text { al.(2018) }\end{array}$ & $\begin{array}{lr}\text { Processes } & \text { and } \\
\text { dynamics of linkage to } \\
\text { care from } \\
\text { mobile/outreach and } \\
\text { facility-based } & \text { HIV } \\
\text { testing models in } \\
\text { hard-to-reach settings }\end{array}$ & Tanzania & $\begin{array}{l}\text { Descrever as populações que } \\
\text { acessam o teste de HIV em } \\
\text { sites de testes baseados em } \\
\text { dispositivos } \\
\text { móveis/divulgação } \\
\text { instalações e (2) compara } \\
\text { processos e dinâmicas desde }\end{array}$ & $\begin{array}{l}\text { Os locais de teste de HIV móveis/de divulgação rurais } \\
\text { atingem mais pessoas do que locais baseados em } \\
\text { instalações, mas chegam a um cliente diferent que é } \\
\text { menos provável ser HIV +ve e parece ser menos } \\
\text { "pronto para ligação". Apesar de mais proativo cuidado } \\
\text { e confeiteiro em sites móveis, a vinculação ao cuidado é } \\
\text { pior do que para os clientes que testaram em sites }\end{array}$ \\
\hline
\end{tabular}




\begin{tabular}{|c|c|c|c|c|}
\hline & $\begin{array}{|lr|}\text { in rural } & \text { Tanzania. } \\
\text { Qualitative } & \text { fndings of } \\
\text { a mixed } & \text { methods } \\
\text { study } & \end{array}$ & & $\begin{array}{l}\text { testes até linkagem cuidado } \\
\text { entre esses dois modelos de } \\
\text { teste do mesmo contexto de } \\
\text { estudo. }\end{array}$ & $\begin{array}{l}\text { baseados em instalações. Nosso fndings destacam uma } \\
\text { combinação de (a) fatores de nível do paciente, } \\
\text { incluindo o estigma; e (b) procedimentos bem } \\
\text { estabelecidos e rotinas para cada etapa entre o teste e o } \\
\text { início do tratamento em locais baseados em instalações. } \\
\text { Longos tempos de espera nos locais de tratamento são } \\
\text { mais uma barreira que deve ser abordada. }\end{array}$ \\
\hline $\begin{array}{l}\text { Rodriguez } \\
\text { \& Dobalian } \\
\text { (2017) }\end{array}$ & $\begin{array}{lr}\text { Provider } & \text { and } \\
\text { administrator } & \\
\text { experiences } & \text { with } \\
\text { providing } & \text { hiv } \\
\text { treatment } & \text { and } \\
\text { prevention } & \text { services in } \\
\text { rural areas } & \end{array}$ & EUA & $\begin{array}{l}\text { (1) adicionar uma nova } \\
\text { dimensão à literatura sobre os } \\
\text { serviços de atenção ao HIV } \\
\text { nas áreas rurais; (2) revelam } \\
\text { fatores que capacidade de } \\
\text { impacto para prestar } \\
\text { assistência ao PLWH em áreas } \\
\text { rurais; (3) sugerir maneiras em } \\
\text { que provedores } \\
\text { administradores r podem } \\
\text { abordar qualquer assistência } \\
\text { médica não atendida } \\
\text { necessidades de PLWH. }\end{array}$ & $\begin{array}{l}\text { Este estudo analisou os contextos únicos, rurais em que } \\
\text { os prestadores e administradores prestam cuidados a } \\
\text { PVHS. Como este estudo incidiu sobre os fornecedores } \\
\text { gerais de cuidado, pesquisas futuras devem também } \\
\text { examinar como estes resultados podem ser semelhantes } \\
\text { ou diferentes entre os fornecedores rurais e urbanas na } \\
\text { Flórida que se especializam na prestação de cuidados } \\
\text { para PVHS }\end{array}$ \\
\hline $\begin{array}{l}\text { Perez, } \\
\text { al.(2016) }\end{array}$ & $\begin{array}{l}\text { Supervised oral HIV } \\
\text { self-testing is accurate } \\
\text { in rural KwaZulu- } \\
\text { Natal, South Africa }\end{array}$ & $\begin{array}{l}\text { África do } \\
\text { Sul }\end{array}$ & $\begin{array}{l}\text { Descrever a implementação do } \\
\text { OralST supervisionado } \\
\text { introduzido pelo conselheiro } \\
\text { em uma área rural alta e } \\
\text { prevalente no HIV. }\end{array}$ & $\begin{array}{l}\text { Este estudo demonstra alto acordo inter-rater, e alta } \\
\text { precisão de supervisionado Oralst. OralST tem } \\
\text { potencial para aumentar a captação de testes de HIV e } \\
\text { pode ser oferecido em clínicas e locais de testes } \\
\text { comunitários na África do Sul rural. Mais pesquisas são } \\
\text { necessárias sobre o potencial de OralST não } \\
\text { supervisionado para aumentar a conscientização do } \\
\text { estado do HIV e a vinculação ao cuidado. }\end{array}$ \\
\hline $\begin{array}{l}\text { Kiene, } \\
\text { al.(2016) }\end{array}$ & 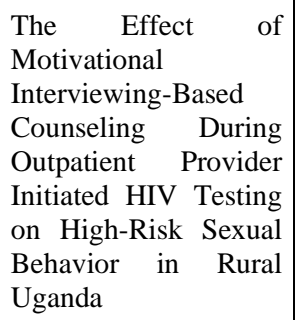 & Uganda & $\begin{array}{l}\text { Avaliar o efeito de um breve } \\
\text { motivacional entrevistando-se } \\
\text { intervenção duranter pitc } \\
\text { ambulatorial na zona rural } \\
\text { uganda em comparação com } \\
\text { Uganda pitc padrão de cuidado } \\
\text { na redução do comportamento } \\
\text { de risco sexual relevante para } \\
\text { a transmissão do HIV. }\end{array}$ & $\begin{array}{l}\text { Esses dados sugerem que motivacional entrevistar } \\
\text { aconselhamento baseado durante pitc pode ser uma } \\
\text { intervenção promissora para reduzir o alto risco } \\
\text { comportamento sexual e potencialmente reduzir o risco } \\
\text { de infecção pelo HIV. }\end{array}$ \\
\hline $\begin{array}{l}\text { Tavares \& } \\
\text { Melo } \\
(2018)\end{array}$ & $\begin{array}{l}\text { The experience of } \\
\text { health professionals } \\
\text { working with HIV- } \\
\text { AIDS in a remote area } \\
\text { of Northeast Brazil }\end{array}$ & Brasil & $\begin{array}{l}\text { Compreender a experiência de } \\
\text { profissionais da saúde que } \\
\text { trabalham em um Serviço de } \\
\text { Atenção Especializada em } \\
\text { HIV/aids num contexto de área } \\
\text { remota, no Nordeste brasileiro. }\end{array}$ & $\begin{array}{l}\text { Este estudo acrescenta ao ressaltar a dimensão local } \\
\text { como um marcador social da diferença que modelava as } \\
\text { experiências dos interlocutores, pois é ali onde as } \\
\text { diretrizes e os princípios da política de saúde são } \\
\text { performados por profissionais, gestores e usuários } \\
\text { compondo materialidades diversas. }\end{array}$ \\
\hline $\begin{array}{l}\text { Iwuji, } \\
\text { al.(2016) }\end{array}$ & $\begin{array}{l}\text { Uptake of Home- } \\
\text { Based HIV Testing, } \\
\text { Linkage to Care, and } \\
\text { Community Attitudes } \\
\text { about ART in Rural } \\
\text { KwaZulu-Natal, South } \\
\text { Africa: Descriptive } \\
\text { Results from the First } \\
\text { Phase of the ANRS } \\
12249 \text { TasP Cluster- } \\
\text { Randomised Trial }\end{array}$ & $\begin{array}{l}\text { África do } \\
\text { Sul }\end{array}$ & 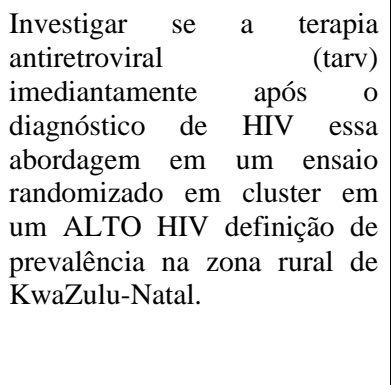 & $\begin{array}{l}\text { O teste domiciliar de HIV foi bem recebido nesta } \\
\text { população rural, embora os homens fossem menos } \\
\text { facilmente contatável em casa; ART imediata foi } \\
\text { aceitável, com boa supressão viral e retenção. No } \\
\text { entanto, apenas cerca de metade das pessoas hiv- } \\
\text { positivas acessaram o cuidado dentro de } 6 \text { mo de sendo } \\
\text { identificados, com quase dois terços acessando o } \\
\text { atendimento por } 12 \text { mo. O atraso observado na } \\
\text { vinculação ao cuidado limitaria os benefícios } \\
\text { individuais e da ART em saúde pública dos testes } \\
\text { universais e tratamento nesta população. }\end{array}$ \\
\hline $\begin{array}{l}\text { Comulada, } \\
\text { et al.(2019) }\end{array}$ & $\begin{array}{l}\text { Using mHealth to } \\
\text { Deliver a Home-Based } \\
\text { Testing and } \\
\text { Counseling Program } \\
\text { to Improve Linkage to } \\
\text { Care and ART } \\
\text { Adherence in Rural } \\
\text { South Africa }\end{array}$ & $\begin{array}{l}\text { África do } \\
\text { Sul }\end{array}$ & $\begin{array}{l}\text { o apresenta o protocolo para } \\
\text { um estudo mHealth que é } \\
\text { piloto de teste de uma } \\
\text { plataforma móvel em } \\
\text { KwaZulu-Natal }(\mathrm{KZN}) \text {, África } \\
\text { do Sul, para melhorar a ligação } \\
\text { aos cuidados e aderência ART } \\
\text { após HTC baseado em casa }\end{array}$ & $\begin{array}{l}\text { Ao examinar a viabilidade e aceitação do nosso } \\
\text { programa atual, esperamos ter uma melhor noção do } \\
\text { equilíbrio ideal de que procedimentos podem ser } \\
\text { automatizados através de protocolos mHealth e que } \\
\text { requer intervenção humana direta para ajudar PLH em } \\
\text { ligar para cuidar e iniciar ART. Este achado é evidente } \\
\text { em outros estudos de base comunitária semelhantes } \\
\text { HIV triagem e destaques como os conceitos de forma a } \\
\text { masculino }\end{array}$ \\
\hline
\end{tabular}




\begin{tabular}{|c|c|c|c|c|}
\hline $\begin{array}{l}\text { Upadhya, et } \\
\text { al.(2016) }\end{array}$ & $\begin{array}{l}\text { What motivates use of } \\
\text { community-based } \\
\text { human } \\
\text { immunodeficiency } \\
\text { virus testing in rural } \\
\text { South Africa? }\end{array}$ & $\begin{array}{l}\text { África do } \\
\text { Sul }\end{array}$ & $\begin{array}{l}\text { Entender as motivações para o } \\
\text { teste do } \quad \text { vírus ra } \\
\text { imunodeficiência humana em } \\
\text { um humano de base } \\
\text { comunitária programa de teste } \\
\text { de vírus da imunodeficiência } \\
\text { na África do Sul rural. }\end{array}$ & $\begin{array}{l}\text { Motivações para testes de vírus de imunodeficiência } \\
\text { humana no nível comunitário são complexo e diferem } \\
\text { de acordo com sexo, idade, local de testes comunitários, } \\
\text { e humano estado do vírus da imunodeficiência. Essas } \\
\text { diferenças podem ser utilizadas para melhorar o foco e } \\
\text { o rendimento de triagem de vírus da imunodeficiência } \\
\text { humana baseada na comunidade. }\end{array}$ \\
\hline
\end{tabular}

Fonte: Dados dos artigos

No quadro tem-se a abordagem dos contendo nome dos Autores, anos, título do artigo, país, objetivo e conclusão de cada um dos 17 artigos incluídos na análise da revisão. Esses dados subsidiaram a discussão, para elaboração deste artigo.

\section{Disponibilidade dos serviços de HIV em áreas rurais}

O acesso aos serviços de saúde pode ser definido como uma união de alguns fatores, entre eles, a identificação da necessidade de atenção à saúde, a procura aos serviços e o alcance aos recursos, sendo que esses serviços devem realmente responder as necessidades identificadas (Vilaça, 2016). Nesse contexto, Giovanella e Fleury (1996) destacam que se o acesso se configura como a capacidade de um grupo obter atenção à saúde, é necessário avaliar a disponibilidade dos recursos e a capacidade de fornecer serviços.

Os resultados do estudo de Allegri et al (2015) mostraram nas comunidades rurais um número reduzido na disponibilidade de testes de HIV para homens, que foi menor em relação as mulheres, pela estruturação do serviço com foco na saúde da mulher.

Isso refletiu em poucos casos diagnosticados de HIV. Constatou-se ainda um agravamento nestes dados, pois, com o número baixo de diagnósticos, os homens não percebem os riscos, portanto, não encontram a necessidade de realizar os testes.

Ao discutir os fenômenos da população rural é necessário considerar os aspectos sociais e as interrelações entre os indivíduos. Nesse contexto, considera-se a influência que a força de trabalho tem para a construção da identidade rural e a relevância do homem nesse cenário. É na figura do homem que culturalmente é depositada a responsabilidade do trabalho, contraposta a figura da mulher que tem responsabilidades com o cuidado ao lar e família (Miranda; Duras e Vasconcelos, 2020)

É nessa dimensão que fica explicita a atitude do homem rural em relação ao meio que convive, refletindo ainda na maneira como o serviço de saúde irá enxergar esse indivíduo.

O estudo de Baker et al (2015), mostrou que a disponibilidade de testes de HIV em uma comunidade rural foi maior em comparação com outros exames diagnósticos para mulheres grávidas, ou seja, considerando as singularidades relacionadas ao gênero e a preocupação dos sistemas de saúde em torno do HIV, é evidente que os serviços se articulam melhor para dispor atenção às mulheres, considerando, inclusive, o processo gestacional.

Treves-Kagan, et al. (2017) trazem essa reflexão relacionada ao gênero a partir da ótica de uma população vulnerável, os imigrantes. Entre os indivíduos estudados a quantidade de homens era maior. Ao considerar que a população imigrante apresenta maiores atitudes de risco e vulnerabilidade, por diversos fatores, incluindo a diminuição da influência familiar e normas culturais e a redução do acesso aos serviços de saúde, especificamente, distanciamento dos programas de prevenção ao HIV H o reflexo de um número maior de indivíduos homens no estudo que não tinham contato com os serviços de saúde.

A partir dos dados expostos, percebe-se que uma diversidade de fatores histórico-culturais e sociodemográficos influenciam para a deficiência na disponibilidade dos serviços de saúde para a população rural, com agravamento para o homem rural. Salientando que essa disponibilidade considera a necessidade especifica que esses indivíduos e o sistema identificam para a procura desses serviços. 
Em relação a essa necessidade individual, é importante considerar que ela é percebida e identificada pelos indivíduos de forma subjetiva, portanto, cada usuário apresentará necessidades de maneiras diferentes, considerando, inclusive, o conhecimento que agregam acerca dos aspectos de saúde-doença e as informações transmitidas pelos profissionais (Vilaça, 2016).

Sendo ass, instala-se então uma problemática em áreas rurais, o nível de conhecimento. O estudo de Calderona et al (2015) revela que em áreas rurais o déficit de conhecimento acerca da transmissão do HIV é maior comparado com as áreas urbanas. Na pesquisa de Gourlay et al (2015) em uma área rural da Tanzania, o acesso aos serviços de prevenção da transmissão vertical do HIV aumentou na medida em que a sociedade avançou na visão sobre o HIV, dirimindo os estigmas sociais.

Portanto, percebe-se que o saber em saúde é importante para que os usuários reconheçam suas necessidades e procurem o serviço, sendo que o alicerce deste saber está no nível de conhecimento adquirido, principalmente, por meio da educação básica, ou seja, quanto maior a escolaridade em áreas rurais, maior a procura pelo sistema de saúde (Arruda; Maia; e Alves, 2018).

\section{Barreiras no acesso aos serviços de HIV}

Entre as diversas limitações da população rural para o acesso aos serviços de saúde, encontra destaque o distanciamento geográfico da população aos locais de oferta, somado aos meios de transporte e dificuldade financeira para arcar com as despesas desse deslocamento (Arruda; Maia \& Alves, 2018).

Ademais, a concentração dos serviços nos grandes centros urbanos, deixando o rural secundário às prioridades de atenção, aumentando o distanciamento para acesso aos serviços prejudicam ainda mais o contato entre os indivíduos e o sistema (Starfield, 2011).

Essa problemática foi constatada em áreas rurais dos estudos da revisão. Hubach et al (2017) mostrou que os usuários da área rural de Oklahama conviviam com barreiras para Prescrição e acesso à Profilaxia pré exposição (PrEP). Essa demanda impunha o deslocamento para localidades metropolitanas, sendo que, a resistência das unidades para dispor do serviço ainda foi evidente, pois, a referência de atendimento era prioritária a usuários da região.

Em outras localidades rurais a PrEP também não está disponível, isso se deve aos fatores sociodemográficos dessas localidades, que comparadas as regiões urbanas, têm a oferta desses serviços dificultada, levando os usuários a longos tempos de transporte para ter acesso ao serviço em áreas urbanas (Cristopher, 2020).

Nos estudos de Orne-Gliermann et al (2016) o transporte foi considerado pelos usuários como uma barreira para ter acesso aos serviços de saúde das clínicas de referência da localidade. Smith et al (2017) também mostraram essa problemática relacionada com o transporte ao constatarem relação entre viajar longas distancias para atendimento e maior probabilidade de infecção por HIV. Ademais os autores afirmam que ter uma facilidade geográfica para acesso aos serviços mostra-se mais importante que um único atendimento recebido com qualidade.

A procura por serviços de saúde na área rural é menor em relação aos indivíduos da área urbana. Ademais, a taxa de pessoas que procuram serviço de saúde na área urbana estando com alguma complicação é maior, ou seja, os indivíduos da área rural tendem a dar entrada na rede de atenção à saúde somente quando tem um quadro agravado (Arruda; Maia \& Alves, 2018).

Essa realidade é resultado de uma série de negligencias sociais, entre elas, o distanciamento do serviço de saúde de áreas rurais e o investimento pessoal insuficiente para efetivar esse transporte. A exemplo, o caso de ribeirinhos amazônicos. Guimarães et al (2020) afirmam que indivíduos dessas áreas têm acesso limitado aos serviços e barreiras na continuidade do cuidado, devido, principalmente, às imposições geográficas e, consequentemente, demandas financeiras instaladas. 
Assim sendo, é necessário que a gestão local passe a enxergar a atenção à saúde da população rural como prioridade. O olhar para o território rural refletirá nas práticas gestoras e na maneira como o serviço será organizado. Longos distanciamentos para acesso aos serviços e dificuldade na continuidade do cuidado são problemáticas instaladas devido a não existência de serviços de saúde dentro dessas comunidades (Sousa; Monteiro \& Bosquat, 2019; Guimarães et al, 2020).

O estudo de Upadhya et al (2016), revelou que os usuários de uma comunidade rural com base comunitária (unidade de saúde) apresentaram melhor conhecimento acerca do seu estado de saúde e riscos de HIV, além de maior motivação para realização de testes de HIV. Ademais, Allegri et al (2015) revela que os usuários com maior renda tiveram menor propensão a temer as barreiras financeiras para acesso aos testes.

\section{Adequação dos serviços à realidade da população rural}

De acordo com Giovanella e Fleury (2016) para as análises que busquem conhecer como o cotidiano das pessoas estão expressos no âmbito do direito à saúde é necessário compreender a relação dos indivíduos com o serviço e suas ações. Parte dessa relação é feita a partir da maneira como o sistema se organiza para atender às demandas que surgem.

Essa organização permeia o planejamento de atividades dentro do serviço. A maior capacidade dos gestores em planejar ações de saúde para essas áreas reflete na qualidade do atendimento frente a população rural, considerando a ampla especificidade e pluralidade existente neste meio (Sousa; Monteiro \& Bosquat, 2019).

Dessa forma, torna-se importante discutir o acesso dos usuários da zona rural aos serviços de HIV a partir da Adequação Funcional, que se caracteriza como as relações criadas pelos serviços para se adequar aos usuários, como sistema de agendamento, horário de funcionamento, serviços de telefone (Damianse, 2016).

Referente a esses fatores, no estudo de Hubach et al (2017), os usuários relataram falta de motivação para procura de serviços de prevenção e diagnóstico de HIV, devido serem direcionados para salas intituladas para atendimento de Doenças Sexualmente Transmissíveis, sendo que nessas comunidades rurais, eles temem o estigma ao serem rotulados pelas doenças. Em contrapartida, Comulada et al (2019) constataram que o acompanhamento por ligação telefônica ou mensagem de texto tem melhor aceitação entre pessoas vivendo com HIV (PVHIV) em comunidades rurais.

Em vista disso, a compreensão do processo de saúde-doença entre populações rurais deve se dar a partir de uma lógica que integre toda a realidade individual e a subjetiva que constroem a maneira como esses indivíduos enxergam o seu meio. Portanto, é necessário compreender o modo que eles enxergam o quadro patológico e a seriedade com que encaram essa vivência (Vasquez, 2019).

Visão essa que é ainda mais latente no caso de doenças estigmatizadas, como o caso do HIV/AIDS, que carrega uma série histórica refletida em uma visão social que ainda estigmatiza a doença e a Pessoa que vive com ela (Parker, 2019).

Assim, na área rural, por questões culturais, refletidas de um pensamento global, percebe-se que os indivíduos têm dificuldade de lidar com o fato de ter HIV, resultando na barreira para adesão às práticas dos serviços de saúde, culminando no déficit no acesso.

Nesse sentido, é de suma importância, a criação de estratégias que visem a adesão da pessoa rural às ações de saúde, considerando a visão que este ser carrega acerca do processo de saúde-doença.

Reafirmando a efetividade de ações que se adaptem a realidade dessas populações, Orne-Gliemann, et al. (2016) mostraram que o atendimento para testagem domiciliar de HIV foi destacado como relevante na comunidade rural do estudo, pois, reduziu a exposição dos usuários que temiam estigmas pela procura aos serviços, além de facilitar o acesso para os que tinham dificuldade de deslocamento pelo distanciamento. 
Por conseguinte, para Iwuji, et al. (2016) a testagem de HIV domiciliar em áreas rurais, também foi bem recebida,.Todavia, a dificuldade destacada foi em alcançar homens para o teste, devido não estarem em casa durante horário de trabalho.

Certamente, a visão particular dos indivíduos rurais frente ao HIV e o medo diante do estigma também refletem na frequência da realização da testagem. Orne-Gliemann, et al. (2016) retratam que os usuários não encontram necessidade de fazer o teste repetidas vezes, pois além de só procurarem o atendimento quando acham que estão com sintomas e ao tomarem alguma atitude de risco, temem o estigma da comunidade e dos profissionais por fazerem testes repetidas vezes e serem julgados por essas atitudes.

A Organização Mundial da Saúde (OMS), considera a testagem rápida em massa de HIV como a melhor estratégia para identificação de casos e início de tratamento, como forma de quebrar a cadeia de transmissão e impedir a disseminação do vírus (WHO, 2019). No Brasil, as ações e campanhas que objetivam testagem rápida em massa vem mostrando grandes resultados positivos ao longo dos anos (Brasil, 2019).

Assim, torna-se imperativo que a testagem seja adotada como estratégia também nas localidades rurais. Para isso, fazse necessária a criação de campanhas e estratégias especificas. Hensen et al (2015) e Perez, et al. (2016), mostraram o autoteste de HIV como uma prática efetiva para adesão de indivíduos de zonas rurais.

O Autoteste de, HIV se baseia em coletas de material oral realizadas pela própria pessoa, sem interferência de algum profissional (Perez et al, 2016). Esse método tem gerado maior adesão dos usuários ao diagnóstico de HIV ao redor do mundo; todavia, duas problemáticas são destacadas: a primeira se refere ao vínculo com o cuidado e a vigilância que é afetado pela descentralização do método diagnóstico. Ademais, convive-se com a dificuldade dos usuários para leitura dos resultados, o que podem gerar viés no diagnóstico (Tahlil et al, 2020).

Sanga et al (2018) destacam outra estratégia positiva em comunidades rurais. A maior aceitabilidade e adesão na testagem de HIV se deram na realização de testes rápidos em unidades móveis. Por fim, as ações através de campanhas e eventos especiais mostraram um número maior de testagem comparadas aos atendimentos diários.

\section{Conclusão}

Finalmente, o estudo permitiu a compreensão dos aspectos inerentes ao fazer saúde em áreas rurais, partindo da ótica do acesso aos serviços de HIV/AIDS nessas áreas, alcançando o objetivo proposto com essa revisão. Dessa forma, concluiu-se que a disponibilidade das ações é deficitária nessas áreas, sendo influenciada pela percepção de necessidade específica que os indivíduos têm nesse contexto, pois, não identificam as problemáticas referentes ao processo de saúde-doença inerentes às doenças infectocontagiosas, sumariamente, ao HIV.

Ademais, há um agravamento entre os homens, pois os serviços de saúde acabam priorizando a mulher, seja nas políticas, quanto nas ações.

Como barreiras ao acesso, identificou-se o distanciamento físico dos serviços e das ações. Em contrapartida, a existência de uma referência em saúde dentro de comunidades rurais, aumenta a motivação e o interesse dos usuários pelas ações. Fica evidente também a necessidade de adaptações dos serviços para alcançar os usuários de zonas remotas, os quais convivem com questões culturais evidentes, entre elas, o estigma social foi destacado como um fator negativo presente nestes grupos sociais. 
Dessa forma, é imperativo que estratégias sejam implementas considerando a diversidade e singularidade desse povo. A exemplo tem-se as estratégias criadas para testagem em algumas localidades, como o autoteste domiciliar e as unidades móveis.

Enfim, o estudo evidenciou que as áreas rurais ao redor do mundo convivem com barreiras no acesso aos serviços de saúde de prevenção e diagnóstico de HIV, trazendo um olhar que deve refletir nas práticas e políticas no Brasil, considerando as características territoriais locais, reiterando a necessidade de políticas e ações que considerem essas especificidades em nível nacional.

Sugere-se então, a partir das reflexões postas neste estudo, a realização de pesquisas científicas que investiguem o acesso aos serviços de saúde por populações de áreas rurais, considerando sua a disponibilidade, acessibilidade, capacidade financeira, adequação funcional e aceitabilidade, principalmente no cenário das doenças infectocontagiosas no Brasil, em destaque o HIV. Nesse contexto, vale salientar a importância dessa visão voltada para as regiões rurais ribeirinhas amazônicas, onde há uma especificidade maior da efetivação de práticas e políticas públicas de saúde.

\section{Referências}

Aromataris, E., \& Munn, Z. (2020). JBI Manual for Evidence Synthesis. JBI.

Allegri, M., Agier, I., Tiendrebeogo, J., Louis, V. R., Yé, M., Mueller, O., \& Sarker, M. (2015). Factors Affecting the Uptake of HIV Testing among Men: a mixed-methods study in rural burkina faso. Public Library of Science (PLoS), Plos One. 10 (7), 1-15.

Alves, M. F. P. (2003) Sexualidade e prevenção de DST/AIDS: representações sociais de homens rurais de um município da zona da mata pernambucana, Brasil. Cad. Saude Publica. 19(2), 429-39.

Anga, E. S., Mukumbang, F. C., Mushi, A. K., Olomi, W., Lerebo, W., \& Zarowsky, C. (2018). Processes and dynamics of linkage to care from mobile/outreach and facility-based HIV testing models in hard-to-reach settings in rural Tanzania. Qualitative findings of a mixed methods study. Aids Research And Therapy. 15(1), 1-15.

Arruda, N. M., Maia, A. G., \& Alves, L. C. (2018). Desigualdade no acesso à saúde entre as áreas urbanas e rurais do Brasil: uma decomposição de fatores entre 1998 a 2008. Cadernos de Saúde Pública. 34(6), 1-14.

Bennett, K. J., Borders, T. F., Holmes, G. M., Kozhimannil, K. B., \& Ziller, E. (2019). What Is Rural? Challenges And Implications Of Definitions That Inadequately Encompass Rural People And Places. Health Aff (Millwood). 38(12), 1985-1992.

Benzakeni, A. S., Garciai, E. G., Sardinha, J. C. G., Pedrosa, V. L., e Paiva, V. (2007). Intervenção de base comunitária para a prevenção das DST/Aids na região amazônica, Brasil. Revista de Saúde Pública, São Paulo. 2(41), 118-126.

Brasil. Ministério da Saúde. Secretaria de Vigilância em Saúde. (2016). Boletim Epidmeiológico: Ano V - $\mathrm{n}^{\mathrm{o}} 1$ - $27^{\mathrm{a}}$ a $53^{\mathrm{a}}$ - semanas epidemiológicas - julho a dezembro de 2015, Ano V - n⿳亠口冋 $1-01^{\mathrm{a}}$ a $26^{\mathrm{a}}$ - semanas epidemiológicas - janeiro a junho de 2016. Ministério da Saúde.

Brasil. Ministério da Saúde. Secretaria de Vigilância em Saúde. (2017). Cinco passos para a prevenção combinada ao HIV na Atenção Básica. Brasília: Ministério da Saúde. 60.

Brasil. Ministério do Planejamento, orçamento e gestão. Instituto Brasileiro de Geografia e Estatística. (2015). Projeto regiões rurais 2015: relatório técnico. Rio de Janeiro: IBGE.

Brasil. Subchefia para assuntos jurídicos. (1938). Decreto-lei $N^{\circ} 311$, de 2 de março de 1938. Dispõe sobre a divisão territorial do país e dá outras providências. Lex: Coleção de Leis do Brasil, 1(1), 438.

Calderón, C. T., Urizar, D. G., Blázquez, C. G., Ferreras, B. A., Rubio, O. R., Montrull, F. B., Rivera, M. O., \& Valero, J. D. A. (2015). Knowledge, attitudes and practices on HIV/AIDS and prevalence of HIV in the general population of Sucre, Bolivia. The Brazilian Journal Of Infectious Diseases, 19(4), 369-375.

Carneiro, F.C., Santos, R. S., Pontes, D. G., Salino, A. V., \& Rebelo, M. A. B. (2009). Oferta e utilização de serviços de saúde bucal no Amazonas, Brasil: estudo de caso em população ribeirinha no Município de Coari. Cad. Saúde Pública, Rio de Janeiro. 25(8): 11827-1838.

Comulada, W. S., Wynn, A., Van Rooyen, H., Barnabas, R. V., Eashwari, R., \& Van Heerden, A. (2018). Using mHealth to Deliver a Home-Based Testing and Counseling Program to Improve Linkage to Care and ART Adherence in Rural South Africa. Prevention Science. 20(1), 126-136.

Ceolin, S., González, J. S., Ruiz, M. D. C. S., \& Heck, R. M. (2017). Bases teóricas de pensamento crítico na enfermagem ibero-americana: revisão integrativa. Texto Contexto Enferm. 26(4), e3830016.

Damianse, P. R. M. (2016). Acesso da pessoa com deficiências múltiplas aos serviços de saúde bucal. Tese (Doutorado). Faculdade de Odontologia de Bauru. Universidade de São Paulo.

Estr. (2018). Metodologia Científica: Ciência, Ensino, Pesquisa. Editora Artes Médicas. 
Giovanella, L., \& Fleury, S. (1996). Serviços de saúde: acesso, processos, avaliação, aspectos econômicos, descrição de caso. In: Política de saúde: o público e o privado, Rio de Janeiro: Editora FIOCRUZ. 175-198.

Gourlay, A., Wringe, A., Todd, J., Cawley, C., Michael, D., Machemba, R., Reniers, G., Urassa, M., \& Zaba, B. (2015). Factors associated with uptake of services to prevent mother-to-child transmission of HIV in a community cohort in rural Tanzania. Sexually Transmitted Infections. 91(7), 520-527.

Guimarães, A. F., Barbosa, V. L. M., Silva, M. P., Portugual, J. K. A., Reis, M. H. S., \& Gama, A. S. M. (2020). Acesso a serviços de saúde por ribeirinhos de um município no interior do estado do Amazonas, Brasil. Revista Pan-amazônica de Saúde. 11(1), 1-7.

Guimarães, P. N., Martin, D., e Quirino, J. (2007). Aids em área rural de Minas Gerais: abordagem cultural. Revista de Saúde Pública. 41(3), 412-418.

Hensen, B., Lewis, J., Schaap, A., Tembo, M., Vera, H. M., Mutale, W., Weiss, H., Hargreaves, J., Stringer, J., \& Ayles, H. (2015). Frequency of HIV-testing and factors associated with multiple lifetime HIV-testing among a rural population of Zambian men. Bmc Public Health. 15(1), 1-14.

Hubach, R. D., Currin, J. M., Sanders, C. A., Durham, A. R., Kavanaugh, K. E., Wheeler, D. L., \& Croff, J. (2017). Barriers to access and adoption of preexposure prophylaxis for HIV prevention among men who have sex with men (MSM) in a relatively rural state. Educacion And Sida Prevention. United States Of America. 4(29), 315-329.

Iwuji, C. C., Orne, G. J., Larmarange, J., Okesola, N., Tanser, F., Thiebaut, R., Rekacewicz, C., Newell, M. L., \& Dabis, F. (2016). Uptake of Home-Based HIV Testing, Linkage to Care, and Community Attitudes about ART in Rural KwaZulu-Natal, South Africa: descriptive results from the first phase of the anrs 12249 tasp cluster-randomised trial. Plos Medicine. 13(8), 1-18.

Kadri, M. R., \& Schweickardt, J. C. (2016). A emergência da Aids no Amazonas. História, Ciências, Saúde-manguinhos. 23(2), $301-319$.

Kerr, P. L. R. S. (2004). Inequality and leprosy in Northeast Brazil: an ecological study. International Journal Of Epidemiology. 33(2), 262-269.

Mendes, E. V. (2016). O acesso à atenção primária à saúde. Brasília, DF: Conselho Nacional de Secretários de Saúde.

Miranda, S. V. C., Duraes, P. S., \& Vasconcellos, L. C. F. (2020). A visão do homem trabalhador rural norte-mineiro sobre o cuidado em saúde no contexto da atenção primária à saúde. Ciência e Saúde Coletiva, 25(4), 1519-1528.

Moher, D., Liberati, A., Tetzlaff, J., \& Altman, D. G. (2009). The PRISMA Group Preferred Reporting Items for Systematic Reviews and Meta-Analyses: The PRISMA Statement. PLoS Med. 6(7): e1000097.

Orne, G. J., Zuma, T., Chikovore, J., Gillespie, N., Grant, M., Iwuji, C., Larmarange, J., Mcgrath, N., Lert, F., \& Imrie, J. (2016). Community perceptions of repeat HIV-testing: experiences of the anrs 12249 treatment as prevention trial in rural south africa. Aids Care. 28(3), 14-23.

Owens, C., Hubach, R. D., Williams, D., Lester, J. Reece, M., \& Dodge, B. (2020). Exploring the Pre-exposure Prophylaxis (PrEP) Health Care Experiences Among Men Who Have Sex With Men (MSM) Who Live in Rural Areas of the Midwest. Aids Education And Prevention. 32(1), 51-66.

Parker, R. (2019). Estigmas do HIV/Aids: novas identidades e tratamentos em permanentes sistemas de exclusão. Revista Eletrônica de Comunicação, Informação e Inovação em Saúde. 13(3), 618-633.

Probst, J., Eberth, J. M., \& Crouch, E. (2019). Structural Urbanism Contributes To Poorer Health Outcomes For Rural America. HEALTH AFFAIRSVOL. $38(12)$.

Pérez, G. M., Steele, S. J., Govender, I., Arellano, G., Mkwamba, A., Hadebe, M., \& Van, C. G. (2016). Supervised oral HIV self-testing is accurate in rural KwaZulu-Natal, South Africa. Tropical Medicine \& International Health. 21(6), 759-767.

Pineda, B. C. (2021). Desarollo humano y desigualdades em salud een la población rural em Colombia. Dossier Odontologia y Sociedad. Univ Odontol, EneJun. 31(66), 97-102.

Smith, M. K., Miller, W. C., Liu, H., Ning, C., He, W., Cohen, M. S., \& Wang, N. (2017). Effects of patient load and travel distance on HIV transmission in rural China: implications for treatment as prevention. Public Library of Science Plos One. 12(5), 1-12.

Soares, C. B., Hoga, L. A. K., Peduzzi, M., Sangaleti, C., Yonekura, T., \& Silva, D. (2014). Integrative review: concepts and methods used in nursing. Rev Esc Enferm USP. 48(2), 335-45.

Sousa, A. L., Monteiro, I. O. P., \& Bosquat, A. (2019). Atenção Primária à Saúde em áreas rurais amazônicas: análise a partir do planejamento do Distrito de Saúde Rural de Manaus. In: Atenção Básica na Região Amazônica: saberes e práticas para o fortalecimento do SUS. Porto Alegre: Rede Unida. Série Saúde \& Amazônia, 8.

Souto, K. M. B., Sena, A. G. N., Pereira, V. O., \& Santos, L. M. (2016). Estado e políticas de equidade em saúde: democracia participativa? Saúde em Debate. $40,49-62$.

Souza, C. C., Mata, L. R. F., Azevedo, C., Gomes, C. R. G., Cruz, G. E. C. P., \& Toffano, S. E. M. (2013). Interiorização do HIV/AIDS no Brasil: um estudo epidemiológico. Revista Brasileira de Ciências da Saúde - Uscs. 11(35), 25-30.

Starfield, B. (2011). The hidden inequity care. International Journal for Equity in Healt.

Tahlil, K. M., ONG, J. J., Rosenberg, N. E., Tang, W., Conserve, D. F., Nkengasong, S., Muessig, K. E., Iwelunmor, J., Ezechi, O., \& Gbaja, B., T. (2020). Verification of HIV Self-Testing Use and Results: a global systematic review. Aids Patient Care And Stds. 34(4), 147-156. 
Research, Society and Development, v. 10, n. 11, e319101119620, 2021

(CC BY 4.0) | ISSN 2525-3409 | DOI: htttp://dx.doi.org/10.33448/rsd-v10i11.19620

Treves, K. S., Ayadi, A. M. E., Pettifor, A., Macphail, C., Twine, R., Maman, S., Peacock, D., Kahn, K., \& Lippman, S. A. (2017). Gender, HIV Testing and Stigma: the association of hiv testing behaviors and community-level and individual-level stigma in rural south africa differ for men and women. Aids And Behavior. 21(9), 2579-2588.

Upadhya, D., Moll, A. P, Brooks, R.P, Friedland, G., \& Shenoi, S. V. (2015). What motivates use of community-based human immunodeficiency virus testing in rural South Africa? International Journal Of Std \& Aids. 27(8), 662-671.

United Nations. Departamento de Assuntos Econômicos e Sociais. (2019). Perspectivas da população Mundial 2019.

Vásquez, C. A. C. (2019). Compreensão Fenomenológica Da Concepção De Saúde/Doença De Ribeirinhos Na Região Metropolitana De Manaus. Dissertação (Mestrado) - Curso de Mestrado em Psicologia, Universidade Federal do Amazonas, Manaus.

Verde, V. V. (2004). Territórios, Ruralidade E Desenvolvimento. Instituto Paranaense de Desenvolvimento Econômico e Social. 1.

Viana, A. L. A., Machado, C. V., Baptista, T. W. F., Lima, L. D., Mendonça, M. H. M., Heimann, L. S., Alburquerque, M. V., Iozzi, F. L., David, V. C., Ibanez, P., \& Frederico, S. (2007). Sistema de saúde universal e território: desafios de uma política regional para a Amazônia Legal. Cadernos de Saúde Pública. 23, S117-S131.

World Health Organization, WHO. (2019). Consolidated guidelines on HIV testing services for a changing epidemic: policy brief. In: Consolidated guidelines on HIV testing services for a changing epidemic: policy brief. 